\title{
Potlatch, absolute hospitality and metaphorization in constructing socioeconomic intercultural reality
}

\author{
Andrey Yakovlevich Bolshunov + , Sofia Andreevna Bolshunova ${ }^{1}$, Aleksandra Sergeevna \\ Proskurina, and Aleksander Georgievich Tyurikov \\ Financial University under the Government of the Russian Federation, Department of Sociology, \\ Moscow, Russia
}

\begin{abstract}
The article reveals and substantiates the following thesis: the "economy of trust" exists exclusively in the context and sphere of specific social relations named potlatch. Potlatch is a traditional gift-giving feast that taken place among the natives of North America. Nowadays there are two points of view on the phenomenon of potlatch. On the one hand, potlatch is claimed to be a reckless waste. On the other hand, it is considered as a clear illustration of trust integration. At this point, the gift-giving process introduces the phenomenon of "absolute hospitality", the embodiment of which is the trust-based space of social integration. Absolute hospitality presupposes the free economic activity of the guest, which is based on unlimited trust and conditioned by nothing. The economy of trust can exist only in such space. Narrativization and metaphorization are essential features of gift-giving space and socio-economic relations developed in it. These are the main forms of construction and interpretation such spaces and relations.
\end{abstract}

Keywords: potlatch, absolute hospitality, metaphorization, cross-cultural communication, trust, narrative, economy of trust

\section{Introduction}

The subject of the article is special mechanisms of social integration in which frameworks of economic relations based on trust are possible. Trust is the significant condition of relations in this sphere because the degree of confidence in the ability to trust and trust behavior define interaction patterns [1]. Kula and potlatch are a clear illustration of trust integration.

Kula is a space outlined by symbolic gift-giving practice in which "natives conduct ordinary trade and make an exchange of different items between separate islands". "Kula unites a significant number of tribes and covers a wide range of actions that are related to each other and influence each other so that they form a single organic whole" [2]. As for the

\footnotetext{
${ }^{1}$ Corresponding author: $\underline{\text { ASBolshunova@,fa.ru }}$

† Died July 21, 2021.
} 
potlatch, it has two images in modern scientific, economic, and political discourses. From the point of view of modern homo economicus potlatch is a reckless waste and even a "lustful investment" in social status, power, wealth, etc. Under this pretext, a merciless struggle was waged with the Indian potlatch from the time of the development of America until the second half of the twentieth century [3]. An alternative point of view is widely presented in the Italian- and Spanish-language literature. According to it the potlatch is a fundamental mechanism of socio-economic integration and even a total anthropological fact (fatto totale) [4-6].

The widespread view is that the circulation of gifts is the characteristic of for archaic economies only. But P. Sloterdijk emphasizes that "the modern world cannot function without the gifts-giving feast" [7]. J. Baudrillard also claims that "kula and potlatch have disappeared, but not their principle" and bases his "theory of objects" on it [8]. Moreover, he argues that "referential cost is destroying and giving way to a purely structural game of value" [9]. These examples point to gift-giving process to show the principles of constructing modern socio-economic and intercultural reality.

\section{Materials and methods}

Research methods include lifeworlds modeling (or social reality modeling) using the semantics of logically possible worlds, intensional and narrative logic. Discourse analysis including narrative analysis, self-understanding discourses in experimental groups, expert interview was also applied. The research was conducted in 2016-2021 inter alia as a part of the research project "Intercultural communication in the global world: modeling experience and application of new theoretical and methodological tools".

\section{$3 \quad$ Results}

The primary result of lifeworlds modeling is the activity-phenomenological model of intercultural communication. The model was applied for socio-economic analysis. So, the researchers highlights main parts of Constructing Socio-Economic Cross-Cultural Reality which are Potlatch, absolute hospitality and metaphorization.

Gifts-giving process introduces the primary intensional meaning (the intensional structure and context) of "absolute hospitality" [10]. The concept was introduced by J. Derrida and embodied in various forms of socio-economic integration [11]. The authors interpret embodiment through the prism of enactivism. The concept of "absolute hospitality" is not a rigid designation and has no reference but it has various embodiments or "objectification" in the terminology of E. Husserl. Kula and potlatch are examples of such embodiments. In a way, this is a "dream", "an attempt to provide hospitality in its semantic limit and completeness" [12]. "Nevertheless, we do not give up the dream of the pure gift, in the same way, that we do not give up the idea of pure hospitality. Even if we know it is impossible and that it can be perverse... If we try to draw a politics after of hospitality from the dream of unconditional hospitality, not only will that be impossible, but it will have perverse consequences. So, despite this perversion, despite this impossibility, we go on dreaming or thinking of pure hospitality, of pure gift" [13].

In economic terms, absolute hospitality presupposes free economic activity of the guest, which is based on unlimited trust and conditioned by nothing. "Absolute hospitality requires me to open my home" and to break up with traditional forms of hospitality based on laws and agreements [12]. It is no accident that during the Kievan Rus' period 
(approximately 9th to 13th century) guests called Russian merchants "torovatyy", which means generous and, at the same time, prone to possess luxuries, excessive riches. Such merchants were associated with gifts. By "guests" authors also mean tourists, investors, partners, and customers. In each of these cases, we are dealing with different embodiments of the intensional meaning of absolute hospitality.

The concepts of gift and absolute hospitality cannot be objectified or converted into secondary intensional meanings or propositions. A gift is something that has the meaning of a gift. Absolute hospitality is something that has the ultimate meaning of hospitality. Therefore, their embodiments require a "re-invention of language". This proccess carried out in the forms of new "narrative substances" deployment generated by it narratives and also metaphorization as a way of expressing the meaning of embodied gift and hospitality [14]. F. Ankersmit considers metaphor as a "linguistic device" by which narrative substances are introduced into the game and individualize the perspective in which reality should be perceived and analyzed. He agrees with S. Humphreys that "metaphors form the core of reality models". So, the narrative offers a metaphorical view of reality [14]. Even the product retains a touch of metaphor because the product is something that has the meaning of the product. This is manifested in the role that narratives play in economic consciousness and behavior $[15,16]$. The meaning of the product is well objectified and has acquired the character of an "objective thought form" as Karl Marx said. It allows us to treat the concept of the product as a proposition. But, in addition to cost as a relationship in which goods are exchanged, there is also a "value" in the price of a good. Value is an expression of meaning of the production which carried out by branding, advertising, the context of demonstrative consumption and other modern forms of "commodity fetishism". In the context of these meanings, the goods in the transformed or as J. Derrida called it perverted forms restore the character of a gift. This fact allows J. Baudrillard arguing that the law of cost has been replaced by the structural law of value, which turns the modern economy into a "simulacrum of the third degree" [9]. In this regard "turn to meanings" and meaning-making in modern management and economic practices could be stated $[17,18]$.

One of the most operationalized approaches articulating the role of narratives in the construction of economic reality is the conviction narrative theory (CNT) [15, 19-21], a set of approaches that characterize decision-making under conditions of radical uncertainty, including the uncertainty caused by the fact that the concepts that actors use are primary intensionals, not rigid designatis. In this situation, the narrative becomes a model of development of the situation constructed by the participants of communication.

\section{Discussion}

The discussion of results can be made through discussing real practices which include described phenomenon. The following are two examples that reflect the results of pilot studies of the construction of socio-economic reality through metaphorization, the narratives of gift-giving and hospitality.

In archaic societies the so-called "exchange of women", constituting relations of kinship, fulfilled the function of social integration. A woman in this "exchange" was not a commodity but a gift (therefore it is in this case better to speak not of the exchange of women but of their circulation); the engagement and then the wedding as an apotheosis of potlatch, a contest in generosity, is a convincing evidence of this. Later, until the modern era, the identity of the gift often reflected the self-consciousness of women and was a product of gender socialization. Such self-consciousness can still be found today, but it is no longer dominant. Our pilot studies in the form of discourse and narratives of 
self-understanding have shown that modern young people tend to think of women in relationships as partners or as commodities, but not as gifts. They easily describe male-female relationships in categories of exchange (bargaining), violence, cooperation, manipulation, but relationships in which women present themselves as a gift are absent. Differences in the perception of marriage as a gift or as a commodity are clearly evident in religious (traditional) and legal understandings of the family. Religion (traditional culture) adheres to an existential interpretation of marriage as a sacrament; in the modern legal interpretation, marriage is increasingly acquiring the features of a contract. Family relations are the most striking confirmation of F. Fukuyama's statement: "legal institutions have replaced trust..." and "there is an inverse relationship between rules and trust" [22].

With this, traditional forms of social integration based on kinship relations, who implied absolute hospitality, are also disappearing. Specifically, this is reflected in the fact that kinship hospitality is increasingly becoming an object of irony, sarcasm (as, for example, in the famous phrase "hello, I am your aunt, I came from Kiev, I will stay with you" or in the post-covid jokes like "vaccination has drawbacks, now relatives can come to us whenever they want and stay as long as they want"). Of course, there is a search for new forms of being together based on an equal exchange, including gift-giving, in which the woman is more of a giver than a gift.

The second example is related to the transformation of the Russian economy. In traditional culture the economic consciousness of the Russians was not based on a binary (poverty/wealth), but on a trinary (poverty/wealth/"torovatost"); torovatyy is the one who is able to contribute to the common cause (for example, donating to the church), help those in need, meet the standards of hospitality, and so on. Russian proverbs prove this convincingly ("wealth is a sin before God, but poverty is a sin before other people", "it is not the rich who feed, but the torovatyy"). From a logical-linguistic point of view, poverty, wealth and torovatost are narrative substances which played a key role in the construction of the "house-building economy". A.P. Sumarokov (18th century) writes: "House-building consists in increasing the abundance... for everyone, not for one person"; "the one who gets rich by the exorbitant work of his subjects... must be called a robber", for he is "a hundred times more harmful than a thief to his country", he is "such a freak of nature, an ignorant..., illiterate creature who honours neither God nor mankind" [23]. Our pilot studies show that today the entrepreneur's torovatost is perceived as nonsense, and entrepreneurs do not understand the torovatost of a traditional merchant (they only perceive it as forms of irrational wastefulness and demonstrative consumption). However, the most convincing evidence of the transformation of Russians' economic consciousness is the fact that the word torovatost and related narratives have almost disappeared from the Russian language.

\section{Conclusion}

Modernity is characterized by "perverted" (J. Baudrillard) forms and degradation of mechanisms of social integration and intercultural communication based on the circulation of gifts. Examples of the transformation of family-marital behavior and the concept of torovatost prove that the narratives related to the circulation of gifts and absolute hospitality are partly out of use, and partly acquired a sarcastic and ironic connotation. Since economy and legal relations are not the areas of trust production per se, based on the analysis we can conclude that the degradation of the discussed mechanisms and forms of social integration is the cause of the crisis of trust in economic, political, social and everyday relations and intercultural communications. 
The article was prepared based on the results of research carried out at the expense of budgetary funds under the state task of the Financial University under the Government of the Russian Federation.

\section{References}

1. E. Fehr, J Europ Econ Assoc, 7(2-3), 235-266 (2009)

2. B. Malinowski, Argonavty zapadnoi chasti Tikhogo okeana [Argonauts of the Western Pacific] (Center for Humanitarian Initiatives, 2015)

3. R. Butler, E. Adams, Potlatch Resistance: An Arendtian Analysis of Tina Loo's Theory of Rhetorical Legal Resistance (2018). Accessed on: September 25, 2021. [Online]. Available:

https://www.academia.edu/37998274/\%20Running_Head_Potlatch_Resistance_Potlatc h_Resistance_An_Arendtian_Analysis_of_Tina_Loos_The\%20ory_of_Rhetorical_Leg al_Resistance

4. M. Esposito, Oikonomia: una genealogia della comunità. Tönnies, Durkheim, Mauss (Mimesis, 2011)

5. M. Gigli, L'economia del dono ai tempi della globalizzazione (2017). Accessed on: September 25, 2021. [Online]. Available:

https://www.academia.edu/38827258/Leconomia_del_dono_ai_tempi_della_globalizza zione

6. Il Dono, Periodico di Ateneo (2013). Accessed on: September 25, 2021. [Online]. Available: https://www.academia.edu/6945921/Il_dono_fatto_sociale_totale

7. P. Sloterdijk, What does a human have that he can give away? An Interview with Peter Sloterdijk by Sjoerd van Tuinen, in J. Brouwer, S. van Tuinen (eds), Giving and Taking: Antidotes to a Culture of Greed (V2 Publishing, Rotterdam, 2014)

8. J. Baudrillard, For a Critique of the Political Economy of the Sign (Verso Books, 2019)

9. J. Baudrillard, Symbolic exchange and death (Sage, 2016)

10. J. Derrida, A. Dufourmantelle, Of hospitality (Stanford University Press, 2000)

11. M. Stapleton, T. Froese, The enactive philosophy of embodiment: From biological foundations of agency to the phenomenology of subjectivity, in Biology and subjectivity, 113-129 (Springer, Cham, 2016)

12. Yu.V. Vatolina, Bul SPb Univ. Intern Rel, 1, 3-7 (2013)

13. J. Derrida, J.L. Marion, R. Kearney, On the gift: a discussion between Jacques Derrida and Jean-Luc Marion, in J.D. Caputo, M.J. Scanlon (eds), God, the gift, and postmodernism, 54-78 (Indiana University Press, 1999)

14. F.R. Ankersmit, Narrative logic (Nijhoff, Dordrecht, 1983)

15. A.D. Brown, E.R. Thompson, Bus Hist, 55(7), 1143-1167 (2013)

16. E. Vaara, J. Tienari, Organization Sci, 22(2), 370-390 (2011)

17. H. De Jaegher, E. Di Paolo, Emerging Comm, 10, 33 (2008)

18. C. Naumer, K. Fisher, B. Dervin, Sense-Making: a methodological perspective, in CHI '08: CHI Conference on Human Factors in Computing Systems, Proceedings of the SIGCHI Conference on Human Factors in Computing Systems, 8 (Florence, Italy, 2008)

19. R. Bronk, Erasmus J Philos Econ, 6(1), 82-107 (2013) 
20. S.G. Johnson, A. Bilovich, D. Tuckett, PsyArXiv (2020). https://doi.org/10.31234/osf.io/urc96

21. D. Tuckett, M. Nikolic, Theory Psych, 27(4), 501-523 (2017)

22. F. Fukuyama, Trust: The social virtues and the creation of prosperity, 99 (Free Press, New York, 1995)

23. A.P. Sumarokov, O domostroitelstve [On Homebuilding], In O.A. Platonov (ed), Economy of the Russian Civilization (IRC, 2008) 